\title{
Somatosensory conduction times and peripheral, cervical and cortical evoked potentials in patients with cervical spondylosis
}

\author{
T GANES
}

From the Department of Neurology, Ullevål Sykehus, Oslo, Norway

SUMMARY Peripheral, cervical and cortical somatosensory evoked potentials after median or ulnar nerve stimulation were recorded in 21 patients with cervical spondylosis with radiculopathy or myelopathy. The test was normal when pain and paraesthesias were the only symptoms, while pathological in radiculopathy with objective neurological signs. The results varied in patients with cervical myelopathy.

Cervical spondylosis is one of the most common conditions encountered in neurology, and is a progressive degenerative disease of the intervertebral disc and the surrounding structures. ${ }^{1}$ The disease can give rise to a diversity of symptoms depending on the severity and location of the pathological processes.

The diagnostic criteria generally used are based on anamnestic information, clinical neurological signs and X-ray changes in the cervical spine. Electrophysiological methods in addition frequently have been used to study spinal cord disorders and root compressions. ${ }^{3}$ 4-12

Somatosensory evoked responses following stimulation of a nerve in the arm can now be recorded with surface electrodes from the brachial plexus, cervical spine and scalp, ${ }^{1013-16}$ and the conduction time between each recording site can thus easily be found. In the present study this method was applied to patients with symptoms of cervical spondylosis. The purpose of the study was firstly to test the clinical diagnostic utility of the method and secondly whether any consistent relation exists between the severity and type of the neurological symptoms (in radiculopathy or myelopathy) and the results of the somatosensory evoked responses.

\section{Methods}

Stimulation Either the median or the ulnar nerves were stimulated at the wrist on both

Address for reprint requests: Dr T Ganes, Department of Neurology, Rikshospitalet, Oslo, Norway

Accepted 7 February 1980 sides, the nerves selected for stimulation being based on the peripheral distribution of pain and paraesthesia. In several patients both the ulnar and the median nerve were stimulated bilaterally. Commercially available bipolar saddle electrodes were used for stimulation of the nerves. The stimulus was delivered by a Medelec constant voltage isolated nerve stimulator. Stimulation frequency was $2 \mathrm{~Hz}$. Strength was adjusted to produce a small muscular twitch in the thenar or hypothenar muscles.

Recording Conventional $9 \mathrm{~mm}$ silver disc EEG electrodes were used and fixed to the skin with Bentonit. The electrodes were placed midclavicularly (Erb's point), and at the spine of the fifth cervical vertebra. The cortical electrodes were placed contralaterally in the hand area and the common reference electrode was attached to the forehead. Tests performed verified that no difference either in signal latency or morphology existed between this reference site and the Fz (10-20 system) reference site. The signals were amplified, averaged and recorded on a conventional Medelec MS 6 EMG machine. High and low pass filters in the amplifiers were set to $16 \mathrm{~Hz}$ and $1.6 \mathrm{KHz}$ respectively in all channels. Sampling time was $40 \mathrm{~ms}$ for Erb and the cervical responses and $80 \mathrm{~ms}$ for the cortical response, giving an A-D sampling rate of 26 and 13 points per ms respectively.

The signal latencies were determined with an adjustable probe and were always measured from the stimulus artifact to peak negativity of the responses. The amplitudes were measured from start of signal to peak negativity. Generally 150 
analog signals from Erb's point and 300 to 600 analog signals from the cervical spine and scalp were averaged.

The patients were sitting relaxed in an arm chair or lying in a bed during the test. Since significant differences in morphology of the cervical evoked response (but not any latency differences) were found with the head in different positions, care was taken to keep the head in a constant position from patient to patient. Cracco and Bickford ${ }^{17}$ have shown that short latency muscle potentials very similar to the genuine cervical cord potentials could be recorded over the cervical spine when the neck extensor muscles were tensioned. In the present study care was therefore taken to avoid tension in the neck muscles by supporting the head during the tests.

In the present study the terms N9, N14 and N20 will be used to denote the maximum negative peaks of the responses from Erb's point, the cervical spine and the scalp regardless of the actual latencies of the responses. The conduction times (CT) as measured between the reak latencies will be denoted N9-N14 and N14-N20 respectively.

Patient sampiing All patients submitted to the neurological department for pain in the neck radiating in one or both arms were subjected to a full neurological examination and X-ray examination of the cervical spine.

The present study comprised only patients with symptoms and signs presumed to be caused by cervical spondylosis. Care was taken to exclude patients with symptoms caused by other disorders such as myositis, thoracic outlet syndromes, tendinitis, brachial plexus lesions etc.

Twenty-one patients were examined, seven females and 14 males. Age ranged from 35 to 67 years, the mean age being 54 and the median age being 55 years. The control test results were taken from a study of 47 persons with no evidence of disorders in the arm or neck. ${ }^{14}$ The matched control group of 12 persons (table 2) was sampled from this control population.

\section{Results}

Classification of patients according to severity of symptoms The patients with cervical spondylosis were classified into three groups according to the severity of their clinical condition. The classification mainly follows that of Brain and Wilkinson, ${ }^{1}$ and was performed in order to see whether any differences in the somatosensory evoked potentials (SEP) results existed between the groups. Several of the patients had bilateral symptoms. Based on clinical evidence and the patient's anamnestic history, the sides were classified as the worse and better side. Common to patients in either of the three groups were $\mathrm{X}$-ray results confirming degenerative changes in the cervical spine typical of cervical spondylosis. ${ }^{1}$

\section{Group I}

This group consisted of six patients with radiating pain and paraesthesias in the arm and fingers as the main symptoms. None of the patients revealed any objective signs such as loss of sensation, weakened reflexes or diminished muscular strength. All patients had typical degenerative changes in the cervical spine; myelography was however performed in only one patient. The mean SEP results and standard deviations of this group are illustrated in table 1. The amplitudes and the latencies of N9, N14 and $\mathrm{N} 20$ as well as the conduction times were normal in all the patients tested (table 1). No SEP differences existed between the impaired and the normal side. The amplitude of the resronses varied considerably from person to person and also bilaterally in the same individual. The amplitude differences however, had no srecific relation to the symptom giving side.

The maximal bilateral latency difference of the

Table 1 Mean response latencies, amplitudes and conduction times following median nerve stimulation in patients with radicular symptoms but no objective neurological signs.

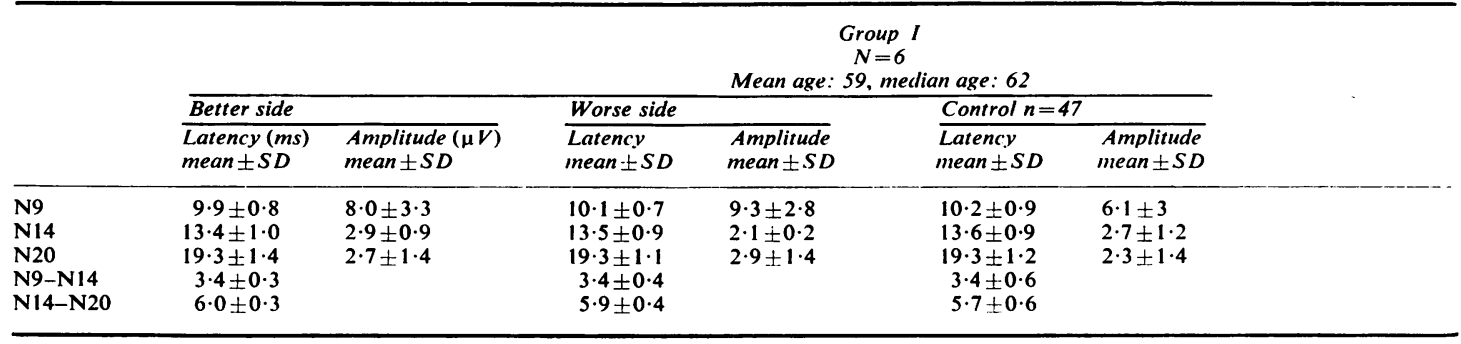



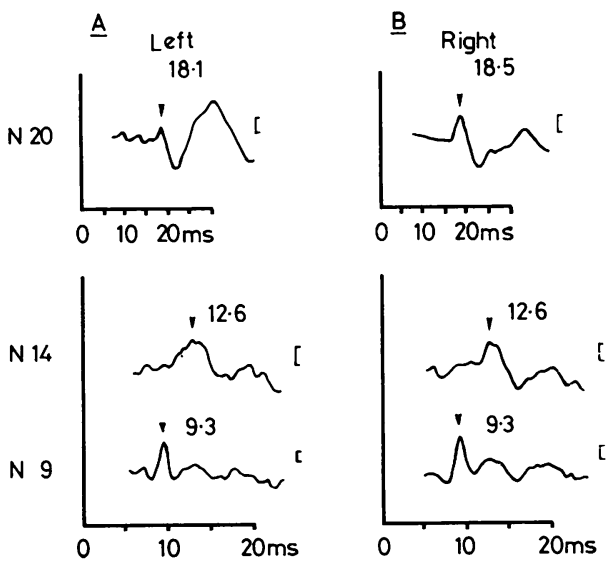

Fig 1 Records following median nerve stimulation from a patient with radicular symptoms in right arm but no objective neurological signs. (A) Evoked responses following left median nerve stimulation at the wrist.

(B) Evoked responses following right median nerve stimulation at the wrist.

Number above records indicates peak latency in $\mathrm{ms}$. Calibration bars represent $2 \mu \mathrm{V}$.

responses were $5 \%$ for N9 and $2 \%$ for $\mathrm{N} 14$ and N20. A typical test result of this group is seen in fig 1 taken from a 43 year old female with pain and paraesthesias radiating from the neck to the right arm and fingers. $\mathrm{X}$-rays revealed marked cervical spondylosis $\mathrm{C}_{5}$ to $\mathrm{C}_{8}$. N9, N14 and N20 were easily recognised following median nerve stimulation in either side, and the latencies, amplitudes and morphology of the responses were normal as were the N9-N14 and N14-N20 conduction times.

\section{Group II}

This group consisted of 12 patients, ten males and two females. Mean age was 51.3 years ranging from 35 to 67 years and median age was 53. All patients in this group had radicular symptoms with pain and paraesthesias aggravated by moving of the neck. Neurological examination in addition revealed objective signs such as loss of sensation, weakening of muscle force and diminished reflexes. According to the distal distribution of the symptoms either the median or the ulnar nerves were stimulated at the wrist on both sides. In nine out of twelve patients symptoms were confined to the median nerve area while three patients mainly had ulnar symptoms. Most of the patients had bilateral symptoms with one side worse than the other and the sides accordingly were graded as the better and the worse. None of the patients had any signs of cervical myelopathy. All patients had X-rays of the cervical spine and ten of twelve had cervical myelography confirming that the cervical roots were affected on one or both sides. In some patients with unilateral clinical symptoms cervical myelography revealed bilateral affection of the root pouches. N9, N14 and $\mathrm{N} 20$ were present in all patients but amplitudes of the responses varied considerably for each patient and also bilaterally in the same patient not always being related to the clinically most impaired side. The maximal individual bilateral amplitude difference was $76 \%, 68 \%$ and $40 \%$ for N9, N14 and N20 respectively.

The largest individual latency differences between the two sides were $17 \%, 14 \%$ and $7 \%$ respectively for N9, N14 and N20. The SEP results were statistically analysed and compared to a control group with normal SEP data. The control group (see methods) consisted of twelve persons and were matched to the patients in group two both with nespect to age and sex. The results are seen in table 2. Only the nine patients with peripheral symptoms confined to the median nerve area, and subsequent median nerve stimulation; were included in table 2 . Asterisks in table 2 indicate that the value differed significantly from the corresponding value in the matched control group. (Student's $t$ test, $\mathrm{p}<0.01$ ). Adding the ulnar nerve group did not alter the distribution of significance stars in table 2.

Although differences both in amplitudes, latencies and conduction times existed between

Table 2 Mean response amplitudes, latencies and conduction times following median nerve stimulation in the wrist in patients with signs of radiculopathy. ${ }^{*}$ Indicates values which are statistically different from the matched control group Student's t test, $p<0.01$ )

\begin{tabular}{|c|c|c|c|}
\hline & \multicolumn{3}{|c|}{$\begin{array}{c}\text { Group II } \\
N=9\end{array}$} \\
\hline & $\frac{\text { Better side }}{\text { Mean } \pm S D}$ & $\frac{\text { Worse side }}{\text { Mean } \pm S D}$ & $\frac{\text { Control } n=12}{\text { Mean } \pm S D}$ \\
\hline \multirow[t]{3}{*}{$\begin{array}{l}\text { N9 } \\
\text { N14 } \\
\text { N20 }\end{array}$} & $\begin{array}{l}4 \cdot 0 \pm 2 \cdot 9 \\
1 \cdot 5 \pm 1 \cdot 6 * \\
2 \cdot 4 \pm 1 \cdot 2\end{array}$ & $\begin{array}{l}4 \cdot 0 \pm 1 \cdot 5 \\
1 \cdot 6 \pm 0 \cdot 6^{*} \\
2 \cdot 4 \pm 1 \cdot 1\end{array}$ & $\begin{array}{l}4 \cdot 5 \pm 2 \cdot 1 \\
2 \cdot 2 \pm 1 \\
2 \cdot 4 \pm 1\end{array}$ \\
\hline & \multicolumn{3}{|c|}{ Latencies $(\mathrm{ms})$} \\
\hline & $\frac{\text { Better side }}{\text { Mean } \pm S D}$ & $\frac{\text { Worse side }}{\text { Mean } \pm S D}$ & $\frac{\text { Control } n=12}{\text { Mean } \pm S D}$ \\
\hline $\begin{array}{l}\text { N9 } \\
\text { N14 } \\
\text { N20 } \\
\text { N9-N14 } \\
\text { N14-N20 }\end{array}$ & $\begin{array}{l}11 \cdot 5 \pm 1 \\
15 \cdot 2 \pm 1 \cdot 3 \\
20.9 \pm 1 \cdot 6 \\
3 \cdot 7 \pm 0.9 \\
5 \cdot 7 \pm 1 \cdot 4\end{array}$ & $\begin{array}{l}11 \cdot 3 \pm 1 \\
15 \cdot 6 \pm 0 \cdot 9^{*} \\
21 \cdot 3 \pm 1 \cdot 4^{*} \\
4 \cdot 3 \pm 0 \cdot 8^{*} \\
5 \cdot 8 \pm 1 \cdot 1\end{array}$ & $\begin{array}{l}10 \cdot 8 \pm 0.9 \\
14 \cdot 2 \pm 1 \\
20.4 \pm 1 \\
3 \cdot 4 \pm 0.5 \\
5.9 \pm 0.5\end{array}$ \\
\hline
\end{tabular}


the worse and the better side in the patient group, the bilateral difference was statistically not significant. When compared to the control group however, amplitude of N14 was significantly reduced in the patient group regardless of the stimulation side. The latencies of N14 and $\mathrm{N} 20$ as well as the N9-N14 conduction time also were significantly prolonged $(p<0.01)$ in the patients when comparing the test results of their most impaired side with the results in the control group.

An example of the results is seen in fig 2 taken from a 42 year old female with symptoms and signs of acute radiculopathy in the right side. Neurological examination revealed pain and paraesthesias radiating from the neck to the index and third finger, reduced sensation in the index finger, reduced force in the triceps muscle and diminished triceps muscle reflexes. The clinical picture pointed to a lesion of the right $C_{7}$ root; myelography was however not performed, but X-ray of the cervical spine confirmed typical degenerative changes in $C_{6}-C_{7}$. The SEP test results following median nerve stimulation revealed a significant reduction of N9 and N14 amplitude on the impaired side (fig 2B). Latiency of N9 on this side was normal while N14 latency was delayed giving a N9-N14 conduction time of $5.1 \mathrm{~ms}$ on this side against $3.5 \mathrm{~ms}$ on the healthy side. Amplitude of N20 was slightly reduced on the impaired side comrared to the healthy side while the latency of $\mathrm{N} 20$ differed but insignificantly (fig $2 \mathrm{~A}, \mathrm{~B}$ ).

Stimulation of the ulnar nerves at the wrist (fig 2C, D) revealed no significant bilateral changes either in response amplitudes or latencies.

\section{Group III}

All patients in this group had clinical evidence of myelopathy with spastic paraparesis, reflex changes in the under extremities and positive Babinski as well as symptoms from the upper extremities. Plain X-rays were obtained and myelography was performed in all cases verifying large degenerative changes in the cervical spine with reduced antero-posterio diameter of the cervical medulla in all but one patient $(\mathrm{OH})$. The results of the SEP test for each patient with cervical myelopathy are listed in table 3. N9, N14 and N2) werc present and easily identifiable in all three patients. In one (RV) the SEP results were normal although neurological examination revealed spasticity with increased reflexes and positive Babinski in the legs as well as radiating pain, paraesthesias and loss of sensibility in both arms and hands. Myelography confirmed large degenerative changes at $C_{5}$ to $C_{7}$ with significantly reduced anterio-posterio diameter of the cord at $\mathrm{C}_{6}-\mathrm{C}_{7}$.

An example of the SEP records from another patient with severe myelopathy (GG) are illustrated in fig 3 . The main clinical signs were spasticity, positive Babinski bilaterally and atrophy of the legs as well as atrophy of $\mathrm{C}_{1:}$ innervated muscles in the right arm. Cervical myelography confirmed severe degenerative changes, reduced A-P diameter of the cervical
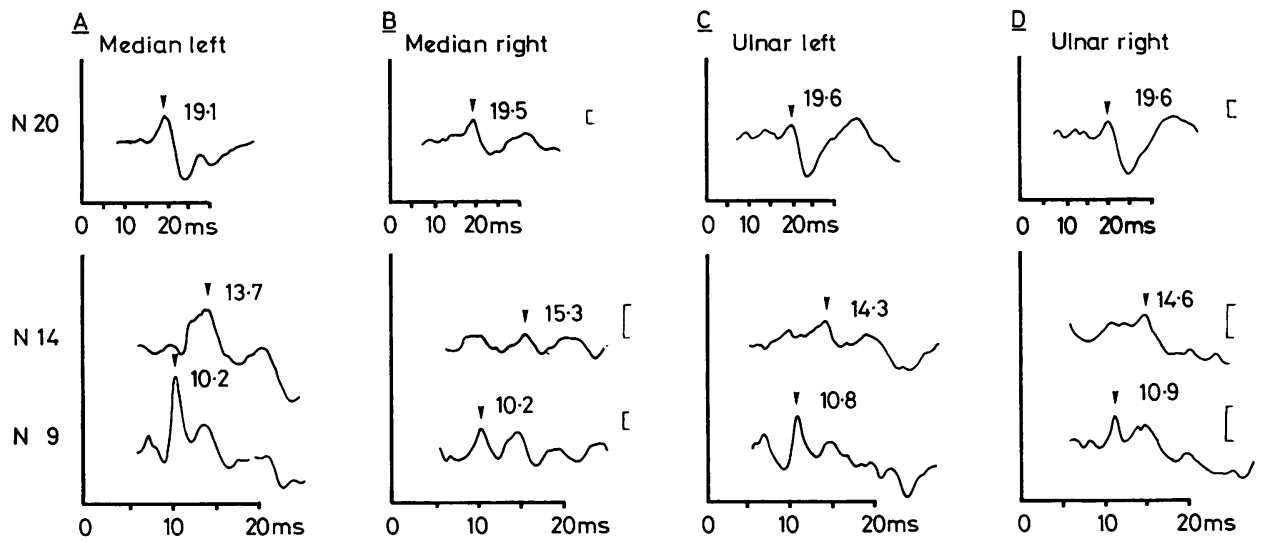

Fig 2 Records from a patient with radiculopathy of the right $C_{7}$ root causing pain, loss of sensation and reduced muscular strength. $(A, B)$ Responses following left and right median nerve stimulation at the wrist. $(C, D)$ Records following left and right ulnar nerve stimulation at the wrist.

Calibration bars for median and ulnar stimulation represent $2 \mu \mathrm{V}$. Number above records indicates peak latency in $\mathrm{ms}$. 
Table 3 Response amplitudes, latencies and conduction times following median nerve stimulation in the wrist of three patients with cervical myelopathy. Responses following stimulation of the right side uppermost for each patient

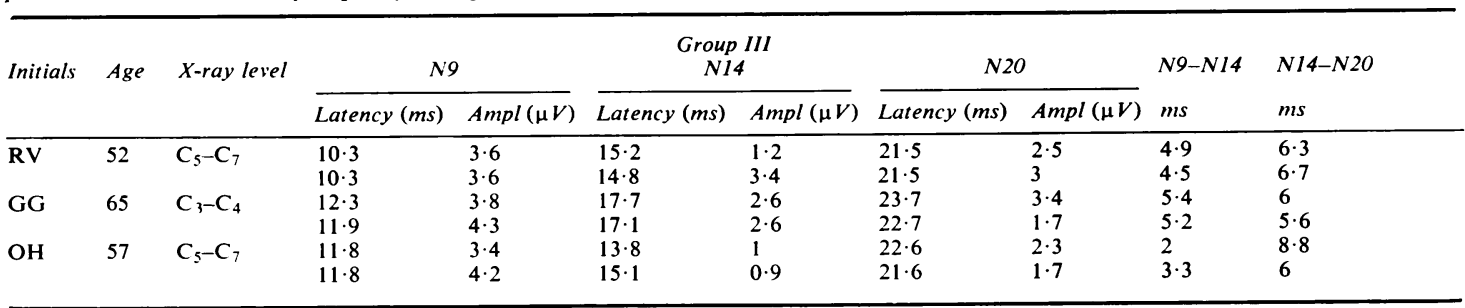

cord at $\mathrm{C}_{3}-\mathrm{C}_{4}$ and lesions of the cervical roots bilaterally at $\mathrm{C}_{5}-\mathrm{C}_{6}$. The SEP records of this patient showed a significant delay of N14 bilaterally following median nerve stimulation (fig $3 \mathrm{~A}, \mathrm{~B})$. Latencies of $\mathrm{N} 20$ were also significantly delayed. N9-N14 conduction time was increased bilaterally while the $\mathrm{N} 14-\mathrm{N} 20$ conduction time was normal, indicating that the increased latency of $\mathrm{N} 20$ was caused by the increased N9-N14 conduction time.

Ulnar stimulation (fig 3B, C) also resulted in pathological SEP results; morphology as well as latency of N9 were pathological bilaterally. The N14 was hardly recognisable and latencies of N20 were significantly prolonged, particularly following stimulation of the right ulnar nerve (fig 3A). The conduction time between N9 and N20 was increased on both sides, most markedly following stimulation of the right ulnar nerve.

The third patient in this group $(\mathrm{OH})$ had a spastic paraparesis and severe degenerative changes in the cervical spine at $\mathrm{C}_{5}-\mathrm{C}_{7}$. The SEP results (table 3 ) were normal except for an increased N14-N20 conduction time following median nerve stimulation on the right side.

\section{Discussion}

Although relatively few patients were examined with the present technique, the data suggest that the main clinical forms of cervical spondylosis are associated with characteristic SEP results.

In the first group of patients with cervical spondylosis, corresponding to Brain \& Wilkinson's " "Acute radiculopathy type 2", the SEP amplitude, latencies and conduction times were normal. This group of patients, however, had no neurological signs of root affection although their subjective symptoms with pain and paraesthesias were clearly radicular.

Since SEP presumably tests the large and fast conducting myelinated afferent fibres only, ${ }^{8} 1819$ the results evidently indicate that no loss of impulse propagation or slowing of impulse velocity exist in the afferent pathways in this
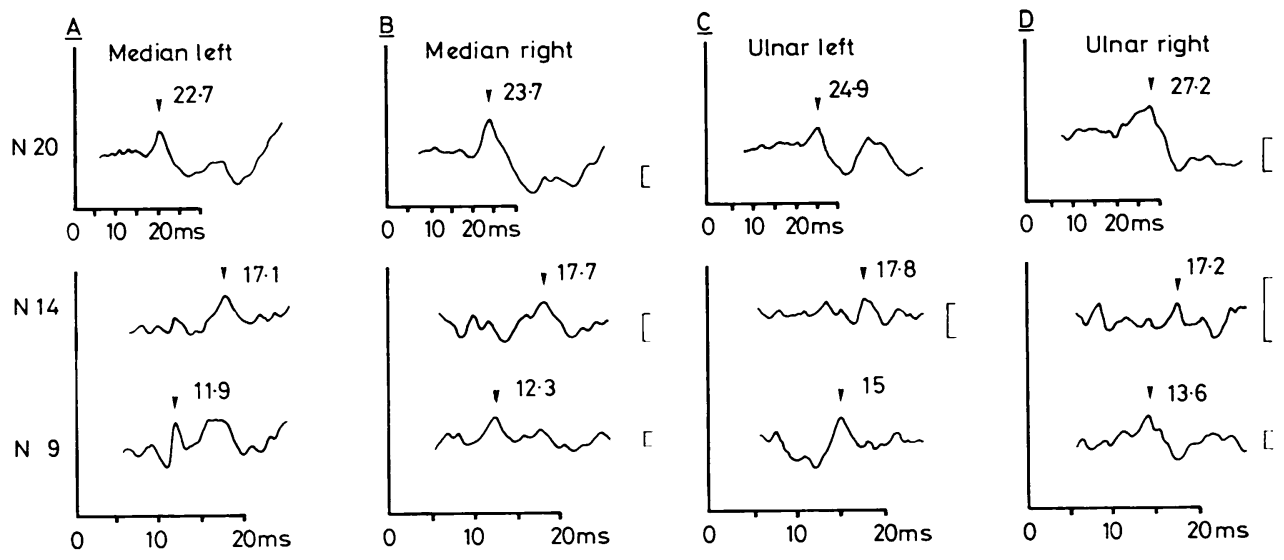

Fig 3 Records from a patient with severe cervical myelopathy. $(A, B)$ Left and right median nerve stimulation at the wrist. $(C, D)$ Left and right ulnar nerve stimulation at the wrist.

Calibration bars for median and ulnar stimulation represent $2 \mu \mathrm{V}$. Note different amplification of $N 14$ in $C$ and D. Number above records indicates peak latencies in ms. 
group. A local demyelination of the cervical dorsal roots without blocking of the impulse transmission obviously would have resulted in a delayed $\mathrm{N} 14$ and increased N9-N14 conduction time, a feature never observed in this patients group. The normal SEP results may indicate that the patients' symptoms either were caused by an altered impulse pattern in otherwise normal large afferent fibres or by a lesion of thin, slowly conducting afferent fibres not tested by the present technique.

The second patient group corresponded mainly to Brain \& Wilkinson's ${ }^{1}$ chronic radiculopathy. Patients in this group had subjective symptoms as well as objective neurological signs of radiculopathy. N9 was present and of normal latency in all patients tested indicating that a normal peripheral impulse reached the cervical roots. In one patient, however, the amplitude of N9 was reduced significantly on the impaired side $(67 \%$ attenuation compared to the healthy side) while the latency was normal. Relatively large bilateral amplitude differences both of N9, $\mathrm{N} 14$ and $\mathrm{N} 20$ have frequently been observed in healthy persons ${ }^{10}{ }^{16}$ but according to Jones ${ }^{10}$ the normal bilateral amplitude variation of $\mathrm{N} 9$ never exceeded $40 \%$. The unilaterally reduced $\mathrm{N} 9$ in this patient thus suggested a diminished number of fast conducting fibres in the plexus indicating that the lesion of the $C_{7}$ root had caused secondary pathological changes in the corresponding plexus fibres.

The most conspicuous finding in group II patients was a reduced amplitude of N14 following median nerve stimulation on either side as well as a unilaterally increased N9-N14 conduction time on the most impaired side. These results agree well with those of Caccia $e t a l^{2}$ recording from the cervical epidural space and reporting that amplitude reduction was the most significant parameter on the diseased side. The fact that no statistically significant bilateral differences existed either of the response amplitude, latencies or conduction time in group two evidently reflects that most patients in this group had bilateral neurological symptoms. This suggestion was further strengthened by the fact that cervical myelography disclosed bilateral lesions of the cervical roots in some of the patients with mainly unilateral symptoms.

The increased N9-N14 conduction time may reflect a delay in impuls.e propagation either in the plexus, dorsal roots or the dorsal column. ${ }^{14}$ Since lesions of brachial plexus invariably resulted in pathological N9 responses, ${ }^{10}$ a SEP test result with normal N9 but increased N9-N14 conduction time points to a lesion proximal to the plexus, either in the cervical roots or dorsal columns. The fact that patients in group II had obvious radiculopathy but no signs, of myelopathy, however, suggested that the increased N9-N14 conduction time was mainly due to a delay in the cervical roots.

The SEP results of the patients with cervical myelopathy varied considerably and the few patients examined allowed no conclusions of what is the characteristic SEP results in this group. The fact that $\mathrm{N} 14$ and $\mathrm{N} 20$ in some patients with cervical myelopathy can be entirely normal while absent in others have previously been pointed out by El-Negamy et al. ${ }^{5}$ Caccia et $a l^{2}$ also have reported normal cervical resronses in a patient with cervical myelopathy.

Autopsy descriptions of spondylotic cervical myelopathy ${ }^{1}$ have clearly demonstrated that any part of the cervical cord can be injured depending on the location and extent of the spondylotic changes. The present method tests but one of the main afferent systems, normal SEP results therefore do not exclude pathological lesions outside the dorsal column/medial lemniscal system. When this system is affected as in the example given in fig 3 and table 3, either the N9-N14 or the N14-N20 conduction times can be increased. The latter presumably reflects the conduction time between the dorsal column nuclei and the cortex, a pathway entirely located intracranially. Why this pathway was affected in a patient with cervical myelopathy has yet to be explained.

Finally the test results of one of the patients with cervical myelopathy (GG) indicated that $a$ significant difference in the afferent conduction times existed between median and ulnar nerve inputs. The result may suggest that the central afferent pathway of the lower cervical roots (ulnar nerve) was more disabled than the central pathway of the upper cervical roots (median nerve) in this patient.

The present data suggest that the somatosensory evoked responses recorded from the brachial plexus, the cervical spine and the scalp can yield valuable diagnostic information in patients with cervical spondylosis. The method evidently can differentiate between plexus lesions and lesions in more proximal structures.

The method also seems to be of value in distinguishing between patients with and without lesions of the large myelinated fibres in the cervical roots, while unreliable in patients with cervical myelopathy. As a first diagnostic test it 
presumably may help to decide which patients should be submitted for myelography and surgical intervention.

\section{References}

1 Brain L, Wilkinson M. Cervical spondylosis and other diseases of the cervical spine. London: William Heineman Medical Books Limited, 1967.

2 Caccia MR, Ubiali E, Andreussi L. Spinal evoked responses recorded from the epidural space in normal and diseased humans. $J$ Neurol Neurosurg Psychiat 1976; 39:962-72.

3 Caldwell HW, Crane CR, Boland GL. Determinations of intercostal motor conduction time in diagnosis of nerve root compression. Arch Phys Med 1968; 49:515-8.

4 Eisen A, Schomer D, Melmed C. An electrophysiological method for examining lumbosacral root compression. Canad J Neurol Sci 1977; 4: $117-23$.

5 El-Negamy E, Sedgwick M. Delayed cervical somatosensory potentials in cervical spondylosis. J Neurol Neurosurg Psychiat 1979; 42:238-41.

6 Ertekin C. Evoked electrospinogram in spinal cord and peripheral nerve disorders. Acta Neurol Scand 1978; 57:329-44.

7 Giblin DR. Somatosensory evoked potentials in healthy subjects and in patients with lesions of the nervous system. Ann NY Acad Sci 1964; 112:93-114.

8 Halliday AM, Wakefield GS. Cerebral evoked potentials with dissociated sensory loss. $J$ Neurol Neurosurg Psychiat 1963; 26:211-19.

9 Halliday AM, The effect of lesions of the afferent pathways and cerebrum on the somatosensory response. In: Remond A, ed. Handbook of Electroencephalography and Clinical Neuro- physiology, Volume 8. Amsterdam: Elsevier Publishing Company, 1975: 129-37.

10 Jones SJ. Investigation of brachial plexus traction lesions by peripheral and spinal somatosensory evoked potentials. J Neurol Neurosurg Psychiat 1979; 42:107-16.

11 Matsukado Y, Yoshida M, Goya T, Shimoy K. Classification of cervical spondylosis or disc protrusion by preoperative evoked spinal electrogram. J Neurosurg 1976; 44:435-41.

12 Perot PL jr. The clinical use of somatosensory evoked potentials in spinal cord injury. Clin Neurosurg 1973; 20:367-71.

13 Ganes T. A study of peripheral, cervical and cortical evoked potentials and afferent conduction times in the somatosensory pathway. Electroencephal Clin Neurophysiol 1980 (In press).

14 Hume AL, Cant BR. Conduction time in central somatosensory pathways in man. Electroencephal Clin Neurophysiol 1978; 45:361-75.

15 Jones SJ. Short latency potentials recorded from the neck and scalp following median nerve stimulation. Electroencephal Clin Neurophysiol 1977; 43:853-63.

16 Matthews WB, Beauchamps M, Small DG. Cervical somatosensory evoked responses in man. Nature 1974; 252:230-32.

17 Cracco RQ, Bickford RG. Somatomotor and somatosensory evoked responses. Arch Neurol 1968; 18:52-68.

18 Desmedt JE. Somatosensory cerebral evoked potentials in man. In: Remond A, ed. Handbook of Electroencephalogy and Clinical Neurophysiology, Volume 9. Amsterdam: Elsevier Publishing Company, 1971: 55-82.

19 Halliday AM. Changes in the form of cerebral evoked responses in man associated with various lesions of the nervous system. Electroencephal Clin Neurophysiol 1967; Suppl. 25, 178-92. 